\title{
Selective listening and threshold for tones appearing on a relevant and on an irrelevant input channel*
}

\author{
TAMAR ZELNIKER $\dagger$, JACK RATTOK, and AVRAHAM MEDEM \\ Tel-Aviv University, Ramat-Aviv, Israel
}

\begin{abstract}
Threshold scores for tones appearing on shadowed and on nonshadowed messages were obtained in order to test whether input presented on an irrelevant channel is attenuated when Ss attend to another channel. Comparisons were made between threshold scores obtained for each ear, when Ss shadowed messages appearing on that ear and when Ss shadowed messages appearing on the contralateral ear. The threshold scores in the two conditions were highly similar. Data are evaluated in the context of auditory target detection, with targets identified by their verbal content vs their physical characteristics.
\end{abstract}

An early attention model by Broadbent (1958) proposed that limitations on the information processing capacity of man leads to the blocking of irrelevant information when the amount of incoming information overloads the system. Difficulties encountered by this model led Treisman (1960) to propose that irrelevant information is attenuated rather than blocked. Her attenuation hypothesis is tested often by comparing responses to the same stimuli presented as relevant and irrelevant, respectively. For this purpose, stimuli frequently are presented simultaneously over different input channels, each channel being made relevant or irrelevant by proper instructions (Lawson, 1966; Treisman \& Geffen, 1967; Treisman \& Riley, 1969; Smith, Donchin, Cohen, \& Starr, 1970).

Smith et al (1970), employing this technique, reported an attenuation of the cortical evoked potentials elicited by irrelevant stimuli. Interestingly, Smith et al found that the attenuation is specific to the stimulus and not to the channel (ear) on which it is presented. But, in contrast with Smith et al, other studies did report an attenuation of stimuli presented on an irrelevant channel. It appears that attenuation was found when target stimuli could be identified on the basis of their verbal content alone (Treisman \& Geffen, 1967; Treisman \& Riley, 1969). In other experiments, in which targets could be identified on the basis of their physical characteristics, no attenuation of irrelevant input was suggested by the data (Lawson, 1966; Treisman \& Riley, 1969; Smith et al, 1970). The latter experiments, however, do not provide a test sensitive enough to detect attenuation; the presentation rate of click stimuli employed by Smith et al was slow (once every $15 \mathrm{sec}$, to each ear) and the target intensity employed by Lawson and by Treisman and Riley was well above threshold.

The present study was designed to test the

\footnotetext{
*This research was supported in part by Grant No. 7446000 from the Faculty of Humanities of Tel-Aviv University to the first author. The authors wish to thank $R$ achel Kissner for her assistance, and Emanuel Donchin, Robert Goodman, and Samuel Himmelfarb for their comments on an earlier version of the manuscript.

tRequests for reprints should be sent to Tamar Zelniker, Department of Psychology, Tel-Aviv University, Ramat-Aviv, Israel.
}

attenuation hypothesis by employing tone targets presented at near-threshold intensities in combination with the classical shadowing procedure commonly used to focus attention selectively on one ear (Treisman, 1960; Treisman \& Geffen, 1967; Treisman \& Riley, 1969). For that purpose, simultaneous verbal messages were presented dichotically to Ss who were required to shadow messages appearing on one ear and to detect tones appearing on either ear. By comparing threshold to tones appearing on one ear at a time when Ss shadowed messages appearing on that ear, and when Ss shadowed messages appearing on the contralateral ear, it was possible to determine whether attenuation of tones appearing on one input channel occurred when Ss attended to another input channel.

\section{METHOD}

\section{Subjects}

Sixteen undergraduate psychology students participated in the experiment. Fourteen of the 16 Ss were right-handed. Twenty additional students, who did not learn to shadow adequately in the first session, were excluded from subsequent experimental sessions.

\section{Stimulus Materials}

Verbal messages included randomly selected disyllabic Hebrew words with the emphasis on the second syllable. The words were arranged in pairs, such that the two words in each pair did not begin or end with the same phoneme, and were grouped into 75 blocks with 16 pairs in each block. A word could not appear more than once in the same block or in consecutive blocks. Each word appeared, on the average, five times in the 75 blocks. One word of each pair was recorded on one track of the tape, and the second word was recorded on the second track such that, when played back, both words appeared simultaneously. The rate of speech presentation was 1.6 words/sec. The mean duration of a word was $512 \mathrm{msec}$, and the mean duration of the interval between consecutive words was $120 \mathrm{msec}$. There was a $5.0-\mathrm{sec}$ interval between consecutive blocks. In addition to the verbal messages, $1,000-\mathrm{Hz}$ tones of $150 \mathrm{msec}$ duration were included in the experiment.

\section{Apparatus}

The system employed to present the stimuli to the Ss included a Sony stereophonic tape recorder, Model 252, a Ferrograph stereophonic tape recorder, Model 720, a timer, S.P. Model $4052 \mathrm{j}$, audioscillator, H.P. Model $200 \mathrm{CD}$, and stereophonic earphones.

The Ferrograph recorder, which served as a mixer, transmitted 
the recorded messages played on the Sony recorder and $1,000-\mathrm{Hz}$ tones produced by the oscillator. The timer determined the duration of the tone as well as the intertone interval. The duration of the tone was constant at $150 \mathrm{msec}$, and the intertone interval varied from 2 to $5 \mathrm{sec}$. The intervals were arranged in a random order, with the limitation that each appear an equal number of times. Fach block of words was assigned a certain intertone interval. The beginning of a series of tones was placed randomly between the second and the fourth words in each block.

Depressing a response button situated in front of the $\mathrm{S}$ turned on a red light in front of $\mathrm{E}$. The $\mathrm{E}$ could observe whether or not $S$ responded following each tone presentation, modify or leave unchanged the intensity of the tone accordingly, and record the S's responses.

\section{Design}

In order to compare the shadowed and nonshadowed input channels, the threshold for tones appearing on the left and on the right ear was measured, once when Ss were shadowing messages presented to the left ear and once when they were shadowing messages presented to the right ear. In this way, it was possible to compare the threshold obtained for one ear when messages appearing on that ear were shadowed and when they were not shadowed. These threshold measures enabled within-ear comparisons which prevented differential sensitivity of the left and right ears from affecting the required comparisons. Two comparisons were available for each $\mathrm{S}$, one for the left and one for the right ear.

Eight Ss began by shadowing messages appearing on the left car and then shadowed messages appearing on the right ear, and eight Ss were assigned the reverse order. Within each of these orders, for four Ss tones appeared initually on the left ear, and for the other four, on the right ear. Two Ss in each of these four groups received the left track of the tape to the left ear and the right track to the right ear, while for the rest of the Ss, the track-ear combination was reversed. There was a total of eight combinations of ear first shadowed by ear receiving the initial series of tones by ear receiving the left track. Two Ss were assigned to each of the eight combinations.

\section{Procedure}

Each $\mathrm{S}$ was tested individually in three sessions. During the first session, Ss were trained to shadow. First, $S$ was presented with verhal messages monaurally and instructed to repeat each word as soon as he heard it. The $S$ practiced until he perfurmed without errors on three consecutive blocks. Follow ing the initial shadowing practice, verbal messages were presented dichotically until $S$ learned to shadow successfully Due to limitation in time availabie for training, those who could not shaduw after 35 blocks were excluded from the experiment. The Ss who learned to shadow in the dichotic presentation condition were given training in shadowing messages appearing on the other ear, initially with messages presented monaurally and subsequently with messages presented dichotically.

About a week following the first session, each of the $16 \mathrm{Ss}$ participated in a second session. The $S$ was presented with three blocks of words and practiced shadowing messages appearing on the appropriate ear, left or right, according to the condition to which he was assigned. Then the $S$ was told that tones would appear occasionally on the left and right ears together with the verbal messages. The $S$ practiced shadowing three blocks of words and responded to tones appearing on the left and right ear at the rate of one tone every $3 \mathrm{sec}$. Finally, $S$ was instructed to continue shadowing one ear and to press the bution as fast as he could whenever he heard a tone appearing on either ear. The threshold was obtained by the method of limits, alternating descending and ascending series.

Intially, a rough threshold for each ear was determined. Subsequently, E measured the threshold, changing the intensity of the tone by 1.25-dB steps. The starting point on the volume control was set five to eight steps below or above the rough threshold for ascending and descending series, respectively. The starting point of ascending and descending series varied according to a prearranged order which was the same for all Ss. A series continued until the $S$ gave three consecutive positive responses in ascending series or until three consecutive tones were missed in descending series. There were 16 series altogether, four ascending and four descending for each ear. All Ss started with descending series with tones appearing alternately on the left and right ear for each successive threshold measurement.

A week later, in the third session, Ss underwent the same procedure as in the second session, shadowing the ear not shadowed in the second session. The same recorded tape was employed in the three sessions.

\section{RESULTS}

The threshold scores were computed on the basis of intensities of the second of three positive responses in ascending series and the second of three misses in descending series. Eight such scores were averaged for each session, for each ear, to obtain the session threshold scores. The four resultant threshold scores for each of the 16 Ss are presented in Table 1. Note that the lower the score, the more "sensitive" the ear.

A two-way analysis of variance of the threshold scores was carried out to evaluate the effect of shadowing (shadowed vs not shadowed) and of the ear (left vs right). Both variables were within-Ss variables. Neither difference proved statistically significant. Neither do the data suggest a significant interaction between the two factors. It can be seen from Table 1 that, of the 32 comparisons of shadowed vs not-shadowed threshold scores, 17 are negative and 15 are positive. Moreover, for 9 of the $16 \mathrm{Ss}$, the difference is positive for one ear and negative for the other ear. Thus, differences in one direction are cancelled by similar differences in the opposite direction. The resultant mean threshold scores for the two ears when shadowed and when not shadowed are extremely similar, with the former (69.55) only slightly lower than the latter (71.47).

Table 1

Threshold Scores for the Left and the Right Ear Separately and for the Two Ears Combined When Shadowed and When Not Shadowed

\begin{tabular}{|c|c|c|c|c|c|c|}
\hline \multirow[b]{2}{*}{ Ss } & \multicolumn{2}{|c|}{ Left Ear } & \multicolumn{2}{|c|}{ Right Ear } & \multicolumn{2}{|c|}{$\begin{array}{c}\text { Mean Left }+ \\
\text { Right Ear }\end{array}$} \\
\hline & $\mathbf{S}$ & NS & $S$ & NS & $\mathrm{S}$ & NS \\
\hline 1 & 69.10 & 83.40 & 73.80 & 69.50 & 71.45 & 76.45 \\
\hline 2 & 88.70 & 73.80 & 63.30 & 84.30 & 76.00 & 79.05 \\
\hline 3 & 64.60 & 73.90 & 49.90 & 64.00 & 57.25 & 68.95 \\
\hline 4 & 53.00 & 54.50 & 55.00 & 54.30 & 54.00 & 54.40 \\
\hline 5 & 84.50 & 80.00 & 79.60 & 73.60 & 82.05 & 76.80 \\
\hline 6 & 78.40 & 71.70 & 75.80 & 69.10 & 77.10 & 70.40 \\
\hline 7 & 74.30 & 64.00 & 64.10 & 74.10 & 69.20 & 69.05 \\
\hline 8 & 93.20 & 74.00 & 73.10 & 74.10 & 83.45 & 74.05 \\
\hline 9 & 57.20 & 55.50 & 59.80 & 72.50 & 58.50 & 64.00 \\
\hline 10 & 58.50 & 52.90 & 56.00 & 67.00 & 57.25 & 59.95 \\
\hline 11 & 78.90 & 79.80 & 60.20 & 81.00 & 69.55 & 80.40 \\
\hline 12 & 80.70 & 66.80 & 67.90 & 83.50 & 74.30 & 75.15 \\
\hline 13 & 55.10 & 84.50 & 82.60 & 59.20 & 68.85 & 71.85 \\
\hline 14 & 77.30 & 82.20 & 86.40 & 89.80 & 81.85 & 86.00 \\
\hline 15 & 55.80 & 77.20 & 69.20 & 72.00 & 62.50 & 74.60 \\
\hline 16 & 73.30 & 62.60 & 65.70 & 62.30 & 69.50 & 62.45 \\
\hline$\overline{\mathrm{X}}$ & 71.41 & 71.05 & 67.68 & 71.89 & 69.55 & 71.47 \\
\hline
\end{tabular}

Note $-S=$ shadowed, $N S=$ not shadowed . 


\section{DISCUSSION}

Threshold scores for tones presented to one ear, when Ss attended to that ear, turned out to be the same as threshold scores for tones presented to the same ear when the Ss' attention was diverted to the contralateral ear. It can be concluded that even with near-threshold signal intensities, there is no attenuation of tone stimuli presented on the irrelevant ear. Contrary to the results obtained in the experiments by Treisman and Geffen (1967) and by Treisman and Riley (1969), in which Ss responded to verbal content of targets, the present results do not support the hypothesis that input arriving on an unattended channel is attenuated.

These data are consistent with results obtained in experiments by Smith et al (1970), Lawson (1966), and Treisman and Riley (1969). Smith et al, while finding a difference in the EP elicited by relevant and irrelevant clicks, failed to find a difference in EP to clicks appearing on the attended and on the unattended ear. Lawson, likewise, found no difference in detection of clicks appearing on the shadowed and the nonshadowed ear. Similarly, Treisman and Riley (1969) reported that the same number of targets was detected on the shadowed and the nonshadowed ear when target words were recorded in a different voice than the rest of the message. It seems, therefore, that when Ss respond to stimuli that can be identified by their physical characteristics rather than by their verbal content, they respond equally well to stimuli appearing on the attended or on the unattended ear. As the present study demonstrates, this is so even when the stimuli are presented at near-threshold intensities.

Results obtained by Moray and Fee (1970) seem to conflict with this view. Moray and Fee found a higher rate of omission of tones presented on the nonshadowed ear $(9.0 \%)$ than on the shadowed ear $(3.4 \%)$. However, because in that experiment the speech in a message was turned off when a tone sounded in the message, speech breaks could have served as signals. Moreover, because Ss could detect a signal or a speech break on the shad owed message both while listening to it and while repeating that message, there was a built-in higher probability of signal detection in the shadowed than in the nonshadowed message. Therefore, the reported higher rate of omission of tones appearing on the nonshadowed ear does not necessarily demonstrate attenuation, as it can be attributed, alternatively, to a methodological artifact.

It should be pointed out that in light of what we know of signal-detection studies, the present experiment might be viewed as confounding sensitivity and response criterion. It appears unlikely that $\mathrm{Ss}$ in this experiment would hold different criteria for each channel for two reasons: first, because tones appeared with equal frequency on each channel, and second, because detecting tones appearing on either channel was of equal importance. However, Treisman (1972), in a recent examination of the data obtained by Moray $(1970 a, b)$, pointed out the feasibility of a double-criterion model. Treisman demonstrates that a model which assumes that different response criteria may be applied to unilateral and bilateral signals accounts best for Moray's results. In conjunction with the proposed multiple-criterion model, we now are exploring the possibility of Ss holding a different criterion for tone signals appearing on shadowed and on nonshadowed messages.

Finally, we still are left with the contradictory results obtained when Ss respond to verbal content or to physical characteristics of targets. Treisman (1969) accounts for the conflicting findings by proposing that physical characteristics serve as the basis for selection and must, therefore, be analyzed prior to the selection of relevant messages. Thus, she concluded that, regardless of input channel, no differences should be found in responding to voice changes, tones, or clicks. In addition, Treisman (1969) proposed the notion of simultaneous operation of several analyzers. According to this notion, she argues that in Treisman and Riley's (1969) experiment, analysis of content (i.e., shadowing) of one message can occur simultaneously with detection of changes in physical characteristics either on the shadowed or un the nonshadowed message. However, it should be pointed out that it is not clear why a single content analyzer does not operate equally well on two simultaneous stimulus inputs (Treisman \& Geffen, 1967; Treisman \& Riley, 1969), whereas an analyzer of physical characteristics (Lawson, 1966; Treisman \& Riley, 1969) does. While these findings might be explained by Treisman's (1969) additional contention that analysis of physical characteristics precedes selection, this explanation has not been tested.

\section{REFERENCES}

Broadbent, D. E. Perception and communication. Oxford: Pergamon Press, 1958.

Lawson, E. A. Decisions concerning the rejected channel. Quarterly Journal of Experimental Psychology, 1966, 18, 260-265.

Moray, N. Time sharing in auditory perception: Effects of stimulus duration. Journal of the Acoustical Society of America, 1970a, 47, 660-661.

Moray, $N$. Introductory experiments in auditory time sharing: Detection of intensity and frequency increments. Journal of the Acoustical Society of America, 1970b, 47, 1071-1073.

Moray, N., \& Fee, M. Selective attention to pure tones and speech. Psychonom ic Science, 1970, 18, 223-224.

Smith, D. E., Donchin, E., Cohen, L., \& Starr, A. Auditory averaged evoked potentials in man during selective binaural iistening. Electroencephalography \& Clinical Neurophysiology, 1970, 28, 146-152.

Treisman, A. M. Contextual cues in selective listening. Quarterly Journal of Experimental Psychology, 1960, 12, 242-248.

Treisman, A. M. Strategies and models of selective attention. Psychological Review, 1969, 76, 282-299.

Treisman, A. M., \& Geffen, G, Selective attention: Perception or response? Quarterly Journal of Experimental Psychology, $1967,19,1-18$.

Treisman, A. M., \& Riley, J. G. A. Is selective attention selective perception or selective response. Journal of Experimental Psychology, 1969, 79, 27-35.

Treisman, M. Detection of binaural tone stimuli: Time sharing or criterion change? Journal of the Acoustical Society of America, 1972, 51, 625-630. accepted February 23, 1974.) 